\title{
Modeling Asymmetric Volatility in the Indian Stock Market
}

\author{
Hojatallah Goudarzi \\ University of Mysore, Mysore, India \\ E-mail: hg502003@yahoo.com \\ C.S. Ramanarayanan \\ Professor of Commerce, University of Mysore, Mysore, India
}

\begin{abstract}
This paper studied the effects of good and bad news on volatility in the Indian stock markets using asymmetric ARCH models during the global financial crisis of 2008-09. The BSE500 stock index was used as a proxy to the Indian stock market to study the asymmetric volatility over 10 year's period. Two commonly used asymmetric volatility models i.e. EGARCH and TGARCH models were used. The BSE500 returns series found to react to the good and bad news asymmetrically. The presence of the leverage effect would imply that the negative innovation (news) has a greater impact on volatility than a positive innovation (news). This stylized fact indicates that the sign of the innovation has a significant influence on the volatility of returns and the arrival of bad news in the market would result in the volatility to increase more than good news. Therefore, we conclude that, bad news in the Indian stock market increases volatility more than good news.
\end{abstract}

Keywords: Asymmetric volatility, Leverage effects, ARCH models

\section{Introduction}

Financial markets, due to their key role in the economic positions of countries, have long been studied from different points of view. In this regard, one key aspect of the stock markets that has long attracted much attention in financial literature is the analysis of the stock returns and its volatility. Volatility refers to the spread of all likely outcomes of an uncertain variable. It is related to, but not the same as; risk .Risk is associated with undesirable outcome, whereas volatility as a measure of strictly for uncertainty could be due to a positive outcome (Poon, 2005).

Ups and downs in the share prices are quite natural in stock market .Stock prices are changed everyday by the market. Basically, share prices change because of supply and demand. Volatility is a symptom of a highly liquid stock market. Pricing of securities depends on volatility of each asset. An increase in stock market volatility brings a large stock price change of advances or declines. Investors interpret a raise in stock market volatility as an increase in the risk of equity investment and consequently they shift their funds to less risky assets. It has an impact on business investment spending and economic growth through a number of channels (Pandin and Jeyanthi, 2009).

The fluctuation of stock prices not only is not destructive per se but also is a sign of market efficiency in stock markets. The main problem with price fluctuations that affects the financial market efficiency is destructive excess volatility that ends crashes and or crisis in financial markets.

Crashes and or crisis is not devoted to developed market and emerging markets includes India aren't excluded from this rule and may faces such an instability sometime. Following the spread of bad news about U.S financial crisis the Indian equity markets have seen a near 60 percent decline in the index and a wiping off of about USD1.3 trillion in market capitalization since January 2008 when the Sensex had peaked at about 21,000. This is primarily due to the withdrawal of about USD 12 billion from the market by foreign portfolio investors between September and December 2008(Kumar, 2009) and its psychological impact on national investors.

The relationship between stock price and its volatility has long interested financial researchers. Empirically, contemporaneous returns and conditional return volatility are negatively correlated. That is, negative (positive) returns are generally associated with upward (downward) revisions of conditional volatility. This empirical phenomenon is often referred to as asymmetric volatility in the literature. The presence of asymmetric volatility is most apparent during stock market crashes when a large decline in stock price is associated with a significance increase in market volatility (Wu.G, 2001). One main theory that considers the relationship between volatility 
and equity price is the leverage effect of Black (1976) and Christie (1982). With the leverage effect, a negative return (declining price) increases financial leverage, making the stock riskier and increasing its volatility.

While the volatility and its relationship with stock price in developed financial markets has been well studied, little attention has been paid towards an extensive study of the volatility of the emerging stock market of India. It is now well known that equities from emerging capital markets have vastly different characteristics than equities from developed capital markets. There are at least four distinguishing features of emerging market returns: higher sample average returns, low correlations with developed market returns, more predictable returns, and higher volatility (Bekaert and $\mathrm{Wu}, 2000$ ). These differences may have important implications for decision making by investors and policy makers. Thus, put emphasis on developed markets finding may mislead policy makers in making proper decisions.

For this reasons, this study aims to investigate the asymmetric relation between stock price and its volatility in India as one of the greatest emerging stock markets. To assess and model the asymmetry in stock market volatility the Threshold ARCH introduced independently by Zakoian (1990) and Glosten, Jagannathan and Rankle (1993) and Exponential GARCH model proposed by Nelson (1991) were used.

We investigated and modeled volatility using two specified nonlinear asymmetric models, EGARCH $(1,1)$ and TGARCH $(1,1)$ and news impact curve. We found that BSE500 returns series exhibit leverage effects. Further, we concluded that the BSE500 in addition to leverage effects exhibit other stylized facts such as volatility clustering and leptokurtosis associated with stock returns on developed stock markets. All in all, we found that TGARCH $(1,1)$ can be possible representative of the asymmetric conditional volatility process for daily returns series of BSE500.

The rest of this paper is organized as follows. Section 2 deals with the asymmetric volatility models considered for this paper. The review of literature is presented in section 3.The description of the BSE500 data and the methodology are presented in section 4 .The empirical analysis and findings are presented in section 5 and section 6 concludes the paper.

\section{Models of Asymmetric Volatility}

One of the primary restrictions of GARCH models is that they enforce a symmetric response of volatility to positive and negative shocks. This arises since the conditional variance in GARCH model is function of the magnitudes of the lagged residuals and not their signs (in other words, by squaring the lagged error in GARCH, the sign is lost). However, it has been argued that a negative shock to financial time series is likely to cause volatility to rise by more than a positive shock of the same magnitude. In the case of equity returns, such asymmetries are typically attributed to leverage effects, whereby a fall in the value of a firm's stock causes the firm's debt to equity ratio, to rise. This leads shareholders, who bear the residual risk of the firm, to perceive their future cash flow stream as being relatively more risky (Brooks, 2002).

To model this phenomenon in this study we applied two model that allow for asymmetric shocks to volatility, the exponential GARCH (EGARCH) model proposed by Nelson (1991) and Threshold ARCH (TARCH) model, introduced by Zakoian (1990) and Glosten, Jagannathan and Runkle (1993) .

\subsection{Egarch Model}

Nelson (1991) proposed the following exponential GARCH (EGARCH) model to allow for leverage effects:

$$
h_{t}=\alpha_{0}+\sum_{i=1}^{p} \alpha_{i} \frac{\left|\varepsilon_{t-i}\right|+\gamma_{i} \varepsilon_{t-i}}{\sigma_{t-i}}+\sum_{j=1}^{q} b_{j} h_{t-j}
$$

Where $h_{t}=\log \sigma_{t}^{2}$ or $\sigma_{t}^{2}=e^{h t}$. Note that when $\varepsilon_{t-i}$ is positive or there is "good news", the total effect of $\varepsilon_{t-i}$ is $\left(1+\gamma_{i}\right)\left|\varepsilon_{t-i}\right|$; in contrast, when $\varepsilon_{t-i}$ is negative or there is "bad news", the total effect of $\varepsilon_{t-i}$ is $\left(1-\gamma_{i}\right)\left|\varepsilon_{t-i}\right|$. Bad news can have a larger impact on volatility, and the value of $\gamma_{i}$ would be expected to be negative. 
Another advantage of the EGARCH model over the basic GARCH model is that the conditional variance $\sigma_{t}^{2}$ is guaranteed to be positive regardless of the values of the coefficients in the above formula because the logarithm of $\sigma_{t}^{2}$ instead of $\sigma_{t}^{2}$ itself is modeled (Zivot and Wang, 2006).

\subsection{TGARCH Model}

Another GARCH variant that is capable of modeling leverage effects is the Threshold GARCH (TGARCH) model, which has the following form:

$$
\sigma_{t}^{2}=\alpha_{0}+\sum_{i=1}^{p} \alpha_{i} \varepsilon_{t-i}^{2}+\sum_{i=1}^{p} \gamma_{i} s_{t-i} \varepsilon_{t-i}^{2}+\sum_{j=1}^{q} b_{j} \sigma_{t-j}^{2}
$$

Where

$$
S t-i=\left\{\begin{array}{llllll}
1 & \mathrm{iff} & \varepsilon & t-i & < & 0 \\
0 & \mathrm{if} & \varepsilon & t-i & \geq 0
\end{array}\right.
$$

That is, depending on whether $\varepsilon_{t-i}$ is above or below the threshold value of zero, $\varepsilon_{t-i}^{2}$ has different effects on the conditional variance $\sigma_{t}^{2}$ : when $\varepsilon_{t-i}$ is positive, the total effects are given by $\alpha_{i} \varepsilon_{t-i}^{2}$; when $\varepsilon_{t-i}$ is negative, the total effects are given by $\left(\alpha_{i}+\gamma_{i}\right) \varepsilon_{t-i}^{2}$. So, one would expect $\gamma_{i}$ to be positive for bad news, to have larger impacts. This model is also known as the GJR model because Glosten, Jagannathan and Runkle (1993) proposed essentially the same model (Zivot and Wang, 2006).

\subsection{Model specification, diagnostic testing and hypothesis}

Before estimating ARCH models for a financial time series, taking two steps is necessory.First it is necessary to check for unit roots in the residuals and second is to test for ARCH effects.

The input series for ARMA needs to be stationary before we can apply Box-Jenkins methodology .The series first needs to be differenced until is stationary. This needs log transforming the data to stabilize the variance. Since the raw data are likely to be non-stationary, an application of ARCH test is not valid. For this reason, it is usual practice to work with the logs of the changes of the series rather than the series itself.

The presence of unit root in a time series is tested using Augmented Dickey- Fuller test. It tests for a unit root in the univariate representation of time series. For a return series $R_{t}$, the $\mathrm{ADF}$ test consists of a regression of the first difference of the series against the series lagged $k$ times as follows:

Or

$$
\Delta r_{t}=\alpha+\delta r_{t-1}+\sum_{i=1}^{p} \beta_{i} \Delta r_{t-i}+\varepsilon_{t}
$$

$$
\Delta r_{t}=r_{t}-r_{t-1} ; r_{t}=1 \mathrm{n}\left(R_{t}\right)
$$

If the ADF test rejects the null hypothesis of a unit root in the return series, that is if the absolute value of ADF statistics exceeds the McKinnon critical value the series is stationary and we can continue to analyze the series.

After checking for unit root and before estimating a full ARCH model for a financial time series, it is necessary to check for the presence of $\mathrm{ARCH}$ effects in the residuals. If there are no $\mathrm{ARCH}$ effects in the residuals, then the ARCH model is unnecessary and misspecified.After checking for unit root and detecting the ARCH effects we can specify asymmetric GARCH model to test the leverage effects.

\subsubsection{EGARCH Model}

To study the leverage effects using EGARCH model we specify the EGARCH $(1,1)$ as follows:

$$
\begin{gathered}
r_{t}=\mu+\phi r_{t-1}+\varepsilon{ }_{t} \\
\ln h_{t}^{2}=\omega+\alpha\left|\frac{\varepsilon_{t-1}}{h_{t-1}}\right|+\gamma \frac{\varepsilon_{t-1}}{h_{t-1}}+\beta \ln h_{t-1}^{2}
\end{gathered}
$$


To accept the Null hypothesis of no leverage effect in EGARCH model, the $\gamma$ coefficient must not be negative, otherwise alternative hypothesis will be accepted. In other words, if the $\gamma$ coefficient is nagative there is evidence of leverage effects in the series.

\subsubsection{TGARCH Model}

To test the asymmetric nature of BSE500 stock index volatility, we specify the TGARCH $(1,1)$ as follows:

$$
\begin{gathered}
r_{t}=\mu+\phi r_{t-1}+\varepsilon_{t} \\
h_{t}=\omega+\alpha \varepsilon_{t-1}^{2}+\gamma \varepsilon_{t-1}^{2} \xi_{t-1}+\beta h_{t-1}
\end{gathered}
$$

Where $\xi_{t-1}=1$ if $\varepsilon_{t-1}<0$ and $\xi_{t-1}=0$ if $\varepsilon_{t-1}>0$.

To accept the Null hypothesisof no leverage effect in TARCH model, the $\gamma$ coefficient must be negative,otherwise alternative hypothesis will be accepted.In other words, if the $\gamma$ coefficient is not nagative there is evidence of leverage effects in the series.

\section{Review of the literature}

Since late twentieth century and particularly after introducing ARCH model by Engle (1982), as said by Bollerslev (1999) and Granger and Poon (2000) several hundred researches that mainly accomplished in developed country and to some extent in developing countries has been done by researchers about volatility using ARCH-type models. Our objective in this section is to give the reader just a glimpse of these studies as follows:

Engle (1982) published a paper that measured the time-varying volatility. His model, ARCH, is based on the idea that a natural way to update a variance forecast is to average it with the most recent squired "surprise"(i.e. the squired deviation of the rate of return from its mean). While conventional time series and econometric models operate under an assumption of constant variance, the ARCH process allows the conditional variance to change over time as a function of past errors leaving the unconditional variance constant. In the empirical application of the $\mathrm{ARCH}$ model a relatively long lag in the conditional variance equation is often called for, and to avoid problems with negative variance parameters a fixed lag structure is typically imposed.

Bollerslev (1986) to overcome the ARCH limitations introduced his model, GARCH that generalized the ARCH model to allow for both a longer memory and a more flexible lag structure. As noted above, in the empirical application of the ARCH model, a relatively long lag in the conditional variance equation is often called for, and to avoid problems with negative variance parameters a fixed lag structure is typically imposed. In the ARCH process the conditional variance is specified as a linear function of past sample variance only, whereas the GARCH process allows lagged conditional variances to enter in the model as well.

Engle, Lilien, and Robins (1987) introduced the ARCH-M model by extending the ARCH model to allow the conditional variance to be determinant of the mean. Whereas in its standard form, ARCH model expresses the conditional variance as a linear function of past squired innovations in this new model they hypothesize that, changing conditional variance directly affect the expected return on a portfolio. Their results from applying this model to three different data sets of bond yields are quite promising. Consequently, they conclude that risk premia are not time invariant; rather they vary systematically with agent's perceptions of underlying uncertainty.

Nelson (1991) extended the ARCH framework in order to better describe the behavior of return volatilities. Nelson's study is important because of the fact that it extended the ARCH methodology in a new direction, breaking the rigidness of the G/ARCH specification. The most important contribution was to propose a model (EARCH) to test the hypothesis that the variance of return was influenced differently by positive and negative excess returns. His study found that not only was the statement true, but also that excess returns were negatively related to stock market variance.

Glosten, Jagannathan and Runkle (1993),to modify the primary restrictions of GARCH-M model based upon the truth that GARCH model enforce a symmetric response of volatility to positive and negative shocks, introduced GJR's (TGARCH) models. They conclude that there is a positive but significant relation between the conditional mean and conditional volatility of the excess return on stocks when the standard GARCH-M framework is used to model the stochastic volatility of stock returns. On the other hand, Campbell's Instrumental Variable Model estimates a negative relation between conditional mean and conditional volatility. They empirically show that the 
standard GARCH-M model is misspecified and alternative specifications provide reconciliation between these two results. When the model is modified to allow positive and negative unanticipated returns to have different impacts on conditional variance, they find that a negative relation between the conditional mean and the conditional variance of the excess return on stocks. Finally, they also find that positive and negative unexpected returns have vastly different effects on future conditional variance and the expected impact of a positive unexpected return is negative.

Engle and $\mathrm{Ng}$ (1993) measure the impact of bad and good news on volatility and report an asymmetry in stock market volatility towards good news as compared to bad news. More specifically, market volatility is assumed to be associated with the arrival of news. A sudden drop in price is associated with bad news on the other hand, a sudden increase in price is said to be due to good news. Engle and $\mathrm{Ng}$ find that bad news create more volatility than good news of equal importance. This asymmetric characteristic of market volatility has come to be known as the "leverage effect". The studies of Black (1976), Christie (1982), FSS (1987), Schwert (1990) and Pagan and Schwert (1989) also explain this volatility asymmetry with the" leverage effect". However, their models do not capture this asymmetry. Engle and Ng (1993) provide new diagnostic tests and models, which incorporate the asymmetry between the type of news and volatility, they advise researchers to use such enhanced models when studying volatility.

Batra (2004) in an article entitled" stock return volatility patterns in India" examined the time varying pattern of stock return volatility and asymmetric Garch methodology. He also examined sudden shifts in volatility and the possibility of coincidence of these sudden shifts with significant economic and political events both of domestic and global origin. Also, he examined stock market cycles for variation in amplitude, duration and volatility of the bull and bear phases over the reference period. His analysis revealed that liberalization of the stock market or the FII entry in particular does not have any direct implications for the stock returns volatility. No structural changes in the stock price volatility around any liberalization event or more importantly around the dates of breaks for volatility in FII sales and purchases in India were observed. The apparent link generally drawn between stock price volatility and the sudden withdrawal or heavy purchase by the FIIs i.e. the volatile FII investment in the stock market did not seem to hold true for India. In all the phases, as delineated by their structural break analysis, the period between 1991:05 and 1993:12 was the most volatile period with the standard deviation of stock returns exceeding that in the other periods. The study also showed that in general over the references period the bull phases are longer, the amplitude of the bull is higher and the volatility in the phases is also higher. He also concluded that the gains during expansions are larger than the losses during the bear phases of stock market cycles. The bull phase, in comparison with its pre liberalization character was more stable in the post liberalization phase. The results of their analysis also, showed that the stock market cycles have dampened in the recent past. Finally, the study showed that volatility has declined in the post liberalization phase for both the bull and bear phase of the stock market cycles.

Kumar (2006) in an article entitled "comparative performance of volatility forecasting models in Indian markets" evaluated the comparative ability of different statistical and economic volatility forecasting models in the context of Indian stock and Forex markets. Based on the out of sample forecasts and the number of evaluated measures that rank a particular method as superior he concluded that it is possible to infer that EWMA will lead to improvements in volatility forecasts in the stock markets and the GARCH $(5,1)$ will achieve the same in the Forex market. As he concluded, his findings were contrary to the findings of Brailsford and Paff (1996) who found no single method as superior, but the results in stock market were similar to the findings of Akigray (1989), McNillian (2001), Anderson and Bollerslev(1998) and Anderson et al (1999) in the Forex market.

Banerjee and Sarkar (2006) in an article entitled" long memory property of stock returns; evidence from India" examined the presence of long memory in asset returns in the Indian stock market. They found that although daily returns are largely uncorrelated, there is strong evidence of long memory in its conditional variance. They concluded that FIGARCH is the best-fit volatility model and it outperforms other Garch type models. They also observed that the leverage effect is insignificant in Sensex returns and hence symmetric volatility models turn out to be superior as they expected.

\section{Data and Methodology}

The required data including 2108 daily closing observation for BSE500 price index covering the period 26/7/2000 through 20/01/2009 were obtained from the Bangalore Stock Exchange, and were based on daily closing prices. The BSE500 returns $\left(r_{t}\right)$ at time $\mathrm{t}$ were defined in the logarithm of BSE500 indices (p), that is, $r_{t}=\log \left(p_{t} / p_{(t-1)}\right)$.Visual inspection of the plot of daily returns series of BSE500 proved very useful. It can be seen that from figure 1 that return fluctuates around mean value that is close to zero. Volatility is high for 
certain time periods and low for other periods. The movements are in the positive and negative territory and larger fluctuations tend to cluster together separated by periods of relative calm. The volatility was highest in 2004 and 2008 . Thus figure 1 shows volatility clustering where large returns tend to be followed by small returns leading to continuous periods of volatility and stability. Volatility clustering implies a strong autocorrelation in squared return.

The number of observation was 2108 . The mean daily return was $1.53 \mathrm{E}-18$. The volatility (measured as a standard deviation) is 0.017142 .There was indication of negative skewness $(\mathrm{Skw}=-0.906)$ which indicates that the lower tail of the distribution was ticker than the upper tail, that is, the index declines occur more often than its increases. The kurtosis coefficient was positive, having high value for the return series $(\mathrm{Kurt}=8.293)$ that is the pointer of leptokurtosis or fat taildness in the underlying distribution. In fact, under the null hypothesis of normality the Jarque-Bera statistic asymptotically follows a Qi-squire distribution with 2 degree of freedom. The computed value of 2750 with P-value of zero rejected the normality assumption due to the high kurtosis indicating fat tail .Q-Q plot in figure 2 also confirm the non-normality of the returns series.

As table. 1 shows ARCH-LM test was statistically significant which indicates the presence of ARCH effect in the residuals of mean equation of BSE 500.The ADF test statistics rejected the hypothesis of unit root in the returns series at $1 \%$ level of significance. A formal application of ADF test on log returns, rejected the null hypothesis of a unit root in the return series. There was rejection at 0.01 level of significance because absolute value of ADF statistics 19.66671 exceeds McKinnon critical value 3.4365. These properties of the BSE500 returns series were consistent with other financial times series.

The ARCH type models were estimated for BSE500 returns series using the robust method of Bollerslev-Wooldridge's quasi-maximum likelihood estimator (QMLE). The information criterion such as AIC, SBIC were used and a set of model diagnostic tests (ARCH-LM test and Q-Statistics) were applied to choose the volatility models which represent the conditional variance of the BSE500 returns series appropriately.

\section{Empirical Analysis and Findings}

As table 1 show, ARCH-LM test was statistically significant which indicates the presence of ARCH effect in the residuals of mean equation of BSE 500. A formal application of ADF test on log returns rejected the null hypothesis of a unit root in the return series. There is rejection at 0.01 level of significance.

The EGARCH $(1,1)$ and TGARCH(1,1)models were estimated for BSE500 returns series using the robust method of Bollerslev-Wooldridge's quasi-maximum likelihood estimator(QMLE) assuming the Gaussian standard normal distribution. Next, the information criteria such as AIC, SBIC values, and a model diagnostic test (ARCH-LM test) were used to choose the volatility model that best modeled the conditional variance of the BSE500 returns series.

The estimation results of TGARCH $(1,1)$ and EGARCH $(1,1)$ models are shown in table 2. The conditional means are significant in both estimated models. For the TGARCH $(1,1)$ and EGARCH $(1,1)$ models the persistence in volatility was very long and explosive suggestive of an integrated process. This was consistent with GJR. The asymmetric effect captured by the parameter estimate $\gamma$ was positive and significant in the TGARCH $(1,1)$ suggesting the presence of leverage effect. The asymmetric term in EGARCH $(1,1)$ model was negative and significant suggesting leverage effects.

After detecting the presence of leverage effects in the series using TGARCH $(1,1)$ and EGARCH(1,1), the SBIC information criterion was applied to select the fittest model to the data. The TGARCH models with different orders (up to 5) were fitted to the daily BSE500 returns. The model with lowest value of SBIC fits the data best. The results are presented in table 3.

Among all SBIC the SBIC of TGARCH $(3,3)$ and TGARCH(1,1) were the lowest respectively, and wrer highly significant, but some of the $\operatorname{TGARCH}(3,3)$ coefficients were negative, therefore the TGARCH$(1,1)$ model was selected and the study concluded that $\operatorname{TARCH}(1,1)$ can be possible representative of the asymmetric conditional volatility process for daily return series of BSE500.

To check the adequacy of the model we first applied the ARCH-LM test up to 10 lags to make sure of the ARCH effects left in the series. The results reported in table 4.

As table 4 shows the F-statistic and $\mathrm{TR}^{2}$ statistics were both statistically insignificant at $5 \%$ significance level.

Thus the study concluded that $\operatorname{TGARCH}(1,1)$ is adequately indicates the volatility asymmetry in the BSE500.The mean and asymmetric volatility model based on TGARCH $(1,1)$ were as follows: 


$$
\begin{gathered}
r_{t}=0.000955+0.152494 r_{t-1}+\varepsilon_{t} \\
\sigma_{t}^{2}=1.69 \mathrm{E}-05+0.050356 \varepsilon_{\mathrm{t}-1}^{2}+0.237949\left(\varepsilon_{\mathrm{t}-1} \varsigma_{t-1}\right)+0.760785 \sigma_{t-1}^{2} \\
\text { Wh here } \varsigma_{t-1}^{2}\left\{\begin{array}{l}
1 \text { fornegative residuals } \\
0 \text { forpositive residuals }
\end{array}\right.
\end{gathered}
$$

Mean and variance of TGARCH $(1,1)$ model 26 July 2000 to 20 January 2009

From the estimated TGARCH model, it is clear that the good news has an impact of 0.050356 magnitude and the bad news has an impact of $(0.050356-0.237949=-0.187593)$. Because the leverage effect is significant the latter is negative. Thus, based on the TGARCH $(1,1)$ model, we could conclude that the bad news in the Indian stock market increases volatility more than good news.

The same process was used to find the fitted EGARCH model for the data. The EGARCH models with different orders (up to 5) were fitted to the daily returns. Similarly, to select the model of EGARCH, we used SBIC criterion. Again, the model with lower value of SBC fits the data best. The results are presented in table 5 .

After all post hoc analysis our result showed that the $\operatorname{EGARCH}(1,1)$ fits the data well. To test the fitness of the model the ARCH-LM test was applied up to 10 lags. The results are presented in the table 6. As table shows the F-statistic and $\mathrm{TR}^{2}$ statistics were both statistically insignificant at $5 \%$ significance level. Thus we concluded that EGARCH (1.1) is adequately indicates the volatility asymmetry in the BSE500.The mean and asymmetric volatility model based on EGARCH $(1,1)$ were as follows

$$
\begin{gathered}
r_{t}=0.000747+0.160603 r_{t-1}+\varepsilon_{t} \\
\log \sigma_{t}^{2}=-0.865253+0.92404210 \mathrm{~g}{\overline{\sigma_{t-1}}}^{2}+0.287839\left|\frac{\overline{\varepsilon_{t-1}}}{\bar{\sigma}_{t-1}}\right|-0.143145\left(\frac{\bar{\varepsilon}_{t-1}}{\bar{\sigma}_{t-1}}\right)
\end{gathered}
$$

Mean and variance equations for EGARCH $(1,1)$ model 26 July 2000 to 20 January 2009

Finally, the news impact curve proposed by Engle and Ng (1993) for EGARCH $(1,1)$ model for BSE500 return series also confirmed the existence of leverage effects in the BSE500 returns series. The plot of news impact curve is as figure 3. As figure indicates, the the effects of news on volatility of BSE500 return series is asymmetrcs. In other words the bad new has more effets on volatility than good news. Therefore, the results of diagnostic tests showed that the models are correctly specified. The ARCH-LM tests were insignificant which confirms the sufficiency of asymmetric models in modeling the serial correlation structure in the conditional mean and variance. Overall, using AIC, SBIC and Log likelihood (LL) as model selection criteria the preferred model was the TGARCH $(1,1)$.

\section{Conclusions}

The volatility of BSE500 stock returns have been investigated and modeled using two nonlinear asymmetric models, EGARCH $(1,1)$ and TGARCH $(1,1)$ and news impact curve. We found that BSE500 returns series exhibit leverage effects and in addition to leverage effects exhibit other stylized facts such as volatility clustering and leptokurtosis associated with stock returns on developed stock markets. Further, we found that TGARCH $(1,1)$ can be possible representative of the asymmetric conditional volatility process for daily returns series of BSE500.Given the expiration of decoupling theory and consequences of global integration of emerging market with developed markets taking the consequences of any possible bad news into account and taking accurate steps before trapping in the financial crisis as it was the case about world financial crisis of 2008 is necessary. In this regards preparing necessary national funds before facing crisis is one alternative. Also, it is recommended that the rules related to common control mechanism i.e. price limits and volume quotas be restructured relative to the status of both the economy and Indian stock market trading cycles. All in all, a growing and increasingly complex market-oriented economy, and its greater integration with global trade and finance, will require deeper, more efficient, and well-regulated financial markets.

\section{References}

Banerjee, A., \& Sarkar, S. (2006). Modeling Daily Volatility of the Indian Stock Market Using Intraday Data, Working Paper No. 588. [Online] Available: http://www.iimcal.ac.in/res/upd\%5CWPS\%20588.pdf.

Batra, A. (2004). Stock Return Volatility Patterns in India, Working Paper no. 124 [Online] Available: http://www.icrier.org/pdf/wp124.pdf. 
Bekaert, G., \& Wu.G. (2000). Asymmetric volatility and risk in equity markets. The Review of Financial Studies, 44, 123-165.

Bollerslev, T. (1986). Generalized autoregressive conditional heteroskedasticity. Journal of Econometrics, 31, 307-327.

Braun, P.A., Nelson, D.B., \& Sunier, A.M. (1995). Good news, bad news, volatility, and betas. Journal of Finance, 50, 1575-1603.

Braun, P.A., Nelson, D.B., \& Sunier, A.M. (1995). Good news, bad news, volatility, and betas. Journal of Finance, 50, 1575-1603.

Brooks, C. (2002). Introductory Econometrics for Finance. Cambridge, Cambridge University Press.

Campbell Y.J., Lo, A.W., \& McKinley, A.C. (2007). The Econometrics of Financial Markets. Delhi, New Age International Publishers.

Engle, F.R. (1982). Autoregressive conditional heteroskedasticity with estimates of the variance of United Kingdom inflation. Econometrica, 50(4), 987-1007.

Engle, F.R., \& Ng, V.K. (1993). Measuring and testing the impact of news on volatility. Journal of Finance, 48, $1749-1778$.

Glosten, L.R., Jagannathan, R., \& Runkle, D.E. (1993). On the relation between the expected value and the volatility of the nominal excess return on stocks. Journal of Finance, 48, 1779-1801.

Gujarati, D.N., \& Sangeeta. (2007). Basic econometrics (4th ed.). The Tata McGraw Hill.

Kummar, S.S.S. (2006). Comparative performance of volatility forecasting models in Indian markets. Decisions, 33(2), 26-40.

Mohan, R. (2008). Global financial crisis and key risks: Impact on india and asia. [Online] Available: http://rbidocs.rbi.org.in/rdocs/Speeches/PDFs/87784.pdf

Mohanty, D. (2009). Global financial crisis and monetary policy response in India. [Online] Available: http://www.bis.org/review/r091217f.pdf

Nelson, D.B. (1991). Conditional heteroskedasticity in asset returns: A new approach. Econometrica, 59, 347-370.

Poon, S.H. (2005). A Practical Guide to Forecasting Financial Market Volatility.West Sussex. John Wiley and Sons.

Poon, S.H., \& Granger, C. (2003). Forecasting volatility in financial markets: A review. Journal of Economic Literature, 41(2), 478-539.

Subbarao, D. (2009). India-managing the impact of the global financial crisis. [Online] Available: http://rbidocs.rbi.org.in/rdocs/Speeches/PDFs/IGFCCII26309.pdf.

Tsuji, C. (2003). Is volatility the best predictor of market crashes? Asia pacific Financial Market, 10,163-185.

Wu, G. (2001). The determinants of asymmetric volatility. The review of financial studies, vol. 14, 3.

Zivot, E., \& Wang. J. (2006). Modeling Financial Time Series With S-Plus, (2nd ed.), Springer.

Zivot, E. (2008). Practical issues in the analysis of univariate GARCH models. [Online] Available: http://faculty.washington.edu/ezivot/research/practicalgarchfinal.pdf.

Table 1. ARCH-LM test

\begin{tabular}{|lccc|}
\hline \multicolumn{4}{|c|}{ ARCH(10) Test } \\
\hline F-statistics & 53.79811 & Probability & 0.0 \\
\hline Obs*R-Squared & 429.9781 & Probability & 0.0 \\
\hline
\end{tabular}


Table 2. The Estimated Asymmetric Volatility Models

\begin{tabular}{|c|c|c|c|c|c|c|}
\hline MODELS & COEFFICIENT & VALUE & P-VALUE & AIC & SBIC & $\begin{array}{l}\text { LOG } \\
\text { LIKELIHOOD }\end{array}$ \\
\hline $\operatorname{TGARCH}(1,1)$ & $\begin{array}{l}\text { Mean Eqt. } \\
\text { Intercept } \\
\text { AR } \\
\text { Variance Eqt } \\
\text { INTERCEPT } \\
\text { ARCH } \\
\text { GARCH } \\
\text { GAMMA }\end{array}$ & $\begin{array}{l}0.000955 \\
0.152494 \\
1.69 \mathrm{E}-05 \\
0.050356 \\
0.760785 \\
0.237949\end{array}$ & $\begin{array}{l}0.0000 \\
0.0000 \\
0.0000 \\
0.1345 \\
0.0000 \\
0.0000\end{array}$ & -5.672932 & -5.656834 & 5982.434 \\
\hline $\operatorname{EGARCH}(1,1)$ & $\begin{array}{l}\text { Mean Eqt. } \\
\text { Intercept } \\
\text { AR } \\
\text { Variance Eqt } \\
\text { INTERCEPT } \\
\text { ARCH } \\
\text { GARCH } \\
\text { GAMMA }\end{array}$ & $\begin{array}{l}0.000747 \\
0.160603 \\
-0.865253 \\
0.287839 \\
0.924042 \\
-0.143145 \\
\end{array}$ & $\begin{array}{l}0.0000 \\
0.0000 \\
0.0000 \\
0.0000 \\
0.0000 \\
0.0000\end{array}$ & -5.669111 & -5.653013 & 5978.408 \\
\hline
\end{tabular}

Table 3. SBIC of TGARCH up to order 5

\begin{tabular}{|c|l|l|l|l|l|}
\hline \multicolumn{6}{|c|}{ Comparisons of the SBC for the TARCH(p,q) model with different combinations of $\mathbf{p}$ and $\mathbf{q}$ for BSE500 } \\
\hline $\mathbf{p}$ & $\mathbf{1}$ & $\mathbf{2}$ & $\mathbf{3}$ & $\mathbf{4}$ & $\mathbf{5}$ \\
\hline $\mathbf{q}$ & & & & & \\
\hline $\mathbf{1}$ & -5.656834 & -5.655665 & -5.653023 & -5.651634 & -5.648082 \\
\hline $\mathbf{2}$ & -5.653286 & -5.653103 & -5.649750 & -5.648139 & -5.644629 \\
\hline $\mathbf{3}$ & -5.653335 & -5.649514 & -5.657879 & -5.644574 & -5.641034 \\
\hline $\mathbf{4}$ & -5.652087 & -5.652099 & -5.654641 & -5.651017 & -5.647923 \\
\hline $\mathbf{5}$ & -5.652491 & -5.650716 & -5.651274 & -5.646467 & -5.644890 \\
\hline
\end{tabular}

Table 4. ARCH-LM test for TGARCH $(1,1)$ model

\begin{tabular}{|c|r|r|r|}
\hline \multicolumn{4}{|c|}{ ARCH-LM test up to 10 lags } \\
\hline F-statistics & 0.587327 & Probability & 0.825551 \\
\hline Obs*R-Squared & 5.887660 & Probability & 0.824612 \\
\hline
\end{tabular}

Table 5. Result of model adequacy check of different EGARCH $(1,1)$ model based on SBIC

\begin{tabular}{|c|l|l|l|l|l|}
\hline \multicolumn{6}{|c|}{ Comparisons of the SBC for the EGARCH(p,q) model with different combinations of $\mathbf{p}$ and $\mathbf{q}$ for BSE500 } \\
\hline $\mathbf{p}$ & $\mathbf{1}$ & $\mathbf{2}$ & $\mathbf{3}$ & $\mathbf{4}$ & $\mathbf{5}$ \\
\hline $\mathbf{q}$ & & & & \\
\hline $\mathbf{1}$ & -5.653013 & -5.652039 & -5.650569 & -5.654766 & -5.657067 \\
\hline $\mathbf{2}$ & -5.649835 & -5.676496 & -5.647136 & -5.665783 & -5.659731 \\
\hline $\mathbf{3}$ & -5.646738 & -5.673987 & -5.638591 & -5.662012 & -5.656209 \\
\hline $\mathbf{4}$ & -5.645630 & -5.670905 & -5.635161 & -5.662051 & -5.652577 \\
\hline $\mathbf{5}$ & -5.648158 & -5.667505 & -5.631037 & -5.653379 & -5.651546 \\
\hline
\end{tabular}


Table 6. ARCH-LM test for EGARCH(1,1) model

\begin{tabular}{|c|r|r|r|}
\hline \multicolumn{5}{|c|}{ ARCH-LM test up to 10 lags } \\
\hline F-statistics & 0.659997 & Probability & 0.762392 \\
\hline Obs*R-Squared & 6.613843 & Probability & 0.761328 \\
\hline
\end{tabular}

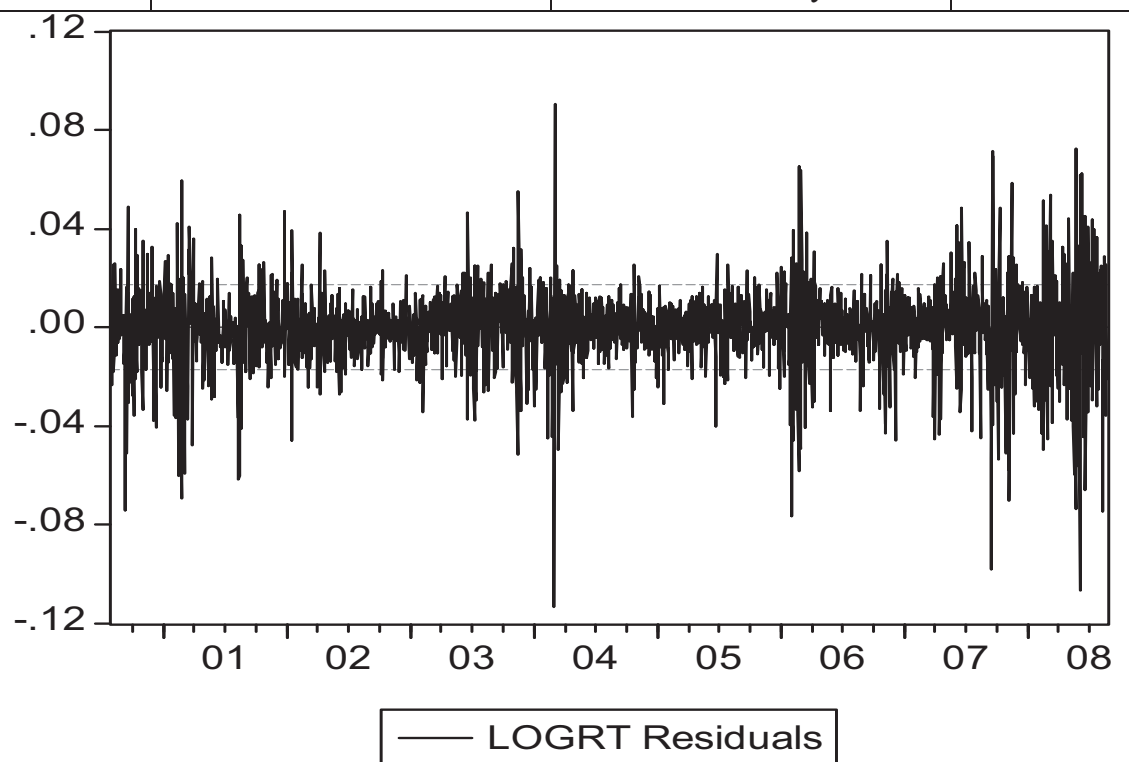

Figure 1. The Residuals of Bse500 Returns

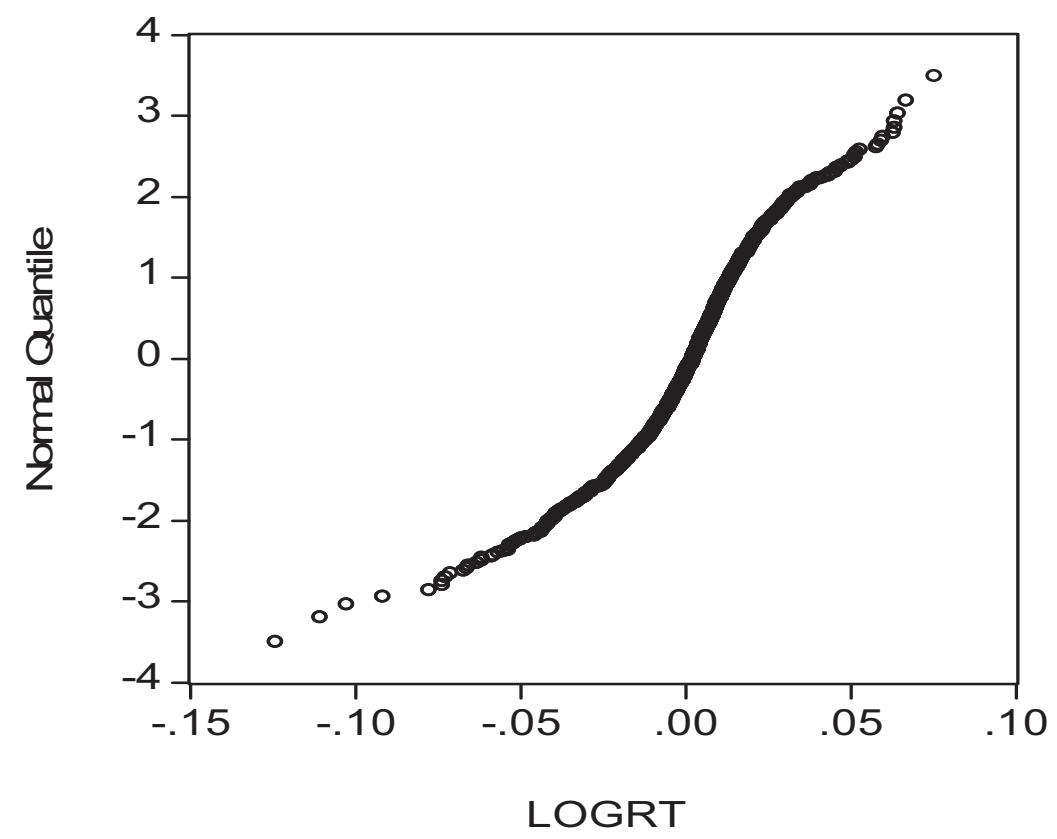

Figure 2. Q-Q Plot of BSE500 Daily Returns Series 


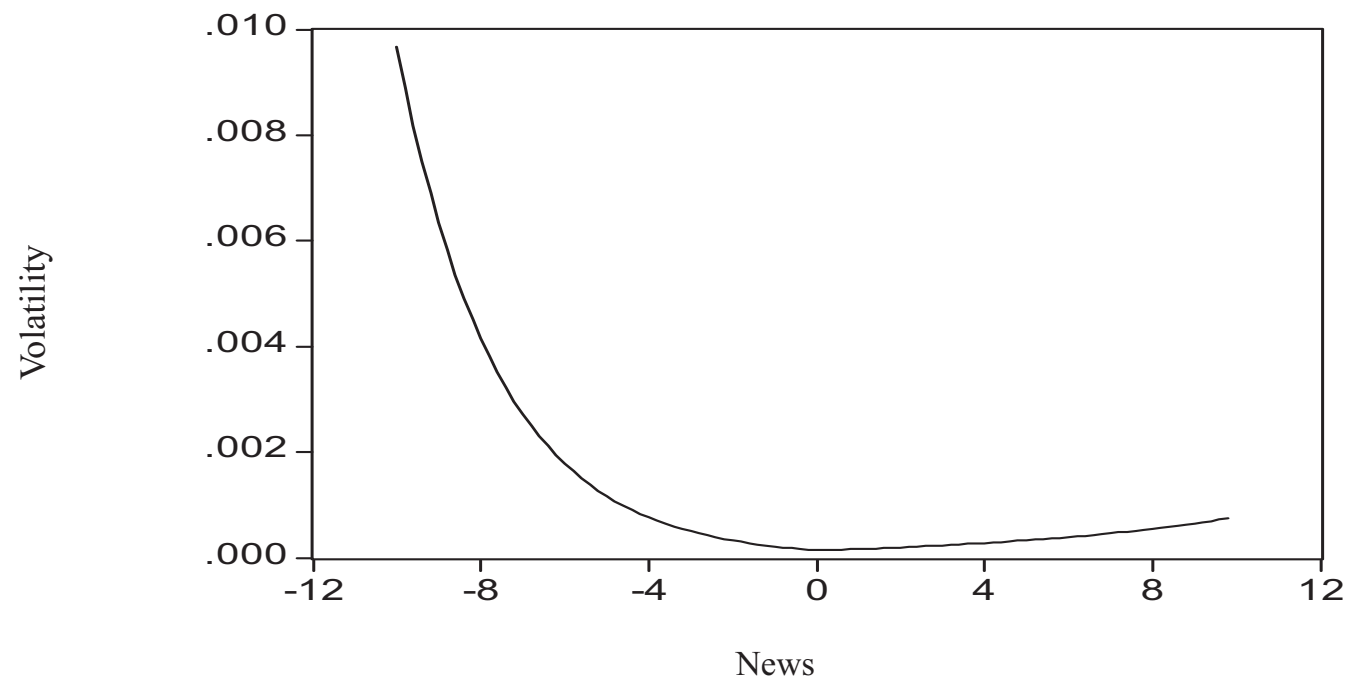

Figure 3. News impact curve of EGARCH model 